SYMPOSIUM

\title{
PERIPHERAL NERVE INJURIES
}

\author{
R. BIRCH, G. BONNEY, J. PAYAN, C. B. WYNN PARRY, A. IGGO
}

From St Mary's Hospital, London

\begin{abstract}
The papers presented here, stimulated by a symposium held in January 1983, were co-ordinated by Rolfe Birch, who has also written the opening section. The symposium is not intended to provide a comprehensive guide to injuries of peripheral nerves but aims to acquaint the reader with today's thinking on certain theoretical and practical aspects and, of equal importance, to warn him of the dangers of iatrogenic injury.
\end{abstract}

\section{LESIONS OF PERIPHERAL NERVES: THE PRESENT POSITION}

\author{
Rolfe Birch
}

Raji and Bowden's important experimental study (1983) on the effects of pulsed electromagnetic field energy on peripheral nerve regeneration draws attention to the considerable volume of new work in this intriguing field. However, much of what has been published recently is based on the study of small animals and, although of considerable interest, is not necessarily applicable to clinical problems: much of it is also repetitive.

Although the prognosis of peripheral nerve injuries must depend upon accurate diagnosis, delay in diagnosis of these injuries is surprisingly common. The patient with a small wound over the course of a median nerve who complains of disturbed sensation in the hand, rather than complete anaesthesia, may be ignored; iatrogenic injuries, whether from scalpel, lack of care in the positioning or padding of the unconscious patient, or from intramuscular or intravenous injections are frequent; the progressive loss of sensation and power from ischaemia may pass unmarked; and the progressive disturbance of sensation and motor function following radiotherapy to the axilla in the treatment of carcinoma of the breast may be attributed, wrongly, to recurrence of the tumour. An important and often neglected sign following injuries of the median, ulnar or sciatic nerve is sympathetic release

R. Birch. FRCS. Consultant Orthopaedic Surgeon G. Bonney, FRCS. Honorary Consulting Orthopaedic Surgeon St Mary`s Hospital, Praed Street. London W2 INY, England. J. Payan. FRCP. Consultant Clinical Neurophysiologist Guy's Hospital, St Thomas Street. London SEI 9RT, England. C. B. Wynn Parry, MBE, FRCP, FRCS. Director of Rehabilitation and Consultant Rheumatologist

Royal National Orthopaedic Hospital, Brockley Hill, Stanmore, Middlesex HA7 4LP. England

A. Iggo, DSc, FRS, Professor of Veterinary Physiology

Royal (Dick) School of Veterinary Studies. Summerhall. Edinburgh EH9 IQH. Scotland.

(1) 1986 British Editorial Society of Bone and Joint Surgery

$0301620 \times 86: 1053 \$ 2.00$ which is constantly present at 48 hours after severance of these nerve trunks (Bonney 1983).

The great volume of meticulous clinical and experimental observation of peripheral nerve injuries carried out in this country during and after the Second World War, which was presented in the MRC memoranda and summarised in Seddon's work (1975), forms the basis of much modern practice. The prognosis for recovery after suture of divided peripheral nerves is governed by certain unalterable factors, the most notable being the age of the patient, the level of the injury and the nature of the injury. Other factors may be modified by those responsible for the patient's care, the most important being the time between injury and repair. Functional recovery in the small muscles of the hand cannot be expected if repair of an ulnar nerve lesion is performed over one year from injury; and if, after severance of the radial nerve, the delay before suture exceeds 18 months, then an appropriate muscle transfer is more likely to improve function than suture of the nerve. The proper selection of the technique of repair and the skill with which it is carried out also are important, but these are not easily defined.

Primary repair. Early repair of cleanly divided nerves produces the best results (Rank, Wakefield and Hueston 1973). Although some degree of anatomical chaos is inevitable at any suture line, the morphology of the nerve is closer to normal after a well-executed primary repair than after any other procedure.

Success in primary repair of divided nerves requires the application of the basic principles of wound management; stability of the skeleton, attention to the soft tissues and the repair of all divided structures are necessary, as is the repair of blood vessels in proximal lesions. There is no doubt that the results of repair of the ulnar and posterior tibial nerves are very much better when the 
appropriate artery also is sutured than when it is ligated. Whether this is because perfusion of the distal nerve trunk and tissues is improved, or whether repair of the vessel relieves tension at the nerve suture line, is unclear, but the ease with which the ulnar nerve can be apposed after repair of the adjacent artery is remarkable. Swelling of the limb, ischaemia of muscles and compression of the nerves are inevitable after closed ruptures of proximal vessels, and must be feared in the hand after major wounds in the upper limb. Decompression by fasciotomy, by incision of the brachial sheath or by release of the anterior carpal ligament reduces this danger.

The aim in repair of divided nerves is coaptation of the neural elements with minimum tension. Magnification assists this: the operating microscope offers a better light source, greater magnification, and greater comfort than a head loupe. Fine sutures and delicate instruments are preferable. An 8-0 filament is appropriate in an epineural repair; if individual bundles are to be coapted by perineural suture, then a $10-0$ filament is preferable. There is no sure clinical evidence that bundle (fascicular) repair is better than simple epineural repair, but the risk of shearing and disorientation of the nerve faces within the epineurium would favour the former technique, particularly in early repair before oedema and fibrosis render the nerve less unstable. Matching of nerve faces in early cases is not difficult; the bundles vary in size, they are often clustered and the pattern of longitudinal blood vessels aids orientation. The nerve stimulator must be regarded as an essential instrument in the operative exploration of peripheral nerves, and in early repair it allows identification of motor bundles. It has also been used in the conscious patient (Hakstian 1968).

Postoperative care is as important as the technique of nerve suture and, if badly conducted, may mar the result. Care is necessary to minimise swelling and relieve pain, and later to prevent stiffness and contracture. The danger of injury to anaesthetic skin must be emphasised to the patient. It is a pity that experimental work in small mammals has suggested that the time necessary for protection of the suture line may be reduced; it is inadvisable to release a nerve trunk from splintage within three weeks of a primary repair, and it is probably wise to prevent hyperextension of adjacent joints for a further three weeks, although active movements of the limb and digits are otherwise encouraged.

Delayed repair. In considering late exploration of peripheral nerve lesions, the most important question is whether the functional outcome of repair is likely to be worthwhile. Perhaps the most important technical question is whether enough of the nerve stump has been resected to reach healthy neural elements proximally and unscarred connective tissue envelopes distally. A gap is inevitable and the harmful effects of tension on nerve repair have been long recognised (Seddon 1975). Much work has been done to define the upper limits of tension in small mammals (Tersiz, Faibisoff and Bruce Williams
1975). In sum, this work suggests that little tension can be allowed. In practice, direct suture is usually impossible in the arm and neck, but at the elbow and forearm gaps of up to $3 \mathrm{~cm}$ can usually be closed by this method. If the nerve faces can be apposed and held by $8-0$ epineural sutures with the elbow and wrist mildly flexed, it seems reasonable to proceed to direct suture. It is true that mobilisation of nerve trunks may facilitate the closure of larger gaps; freeing the median nerve from the pronator teres and from the lacertus fibrosus may gain a centimetre or so, while anterior transposition of the ulnar nerve may gain up to $3 \mathrm{~cm}$. However, mobilising nerve trunks to gain length is a tedious business. The plane of dissection should be outside the adventitia, preserving vascular pedicles. The nerve stimulator is essential to help preserve proximal branches.

Injuries of the sciatic nerve and its trunks are commonly caused by traction lesions and a large gap is the rule. This poses particular problems, for the size of the sciatic nerve is such that autogenous nerves for grafting are inadequate and the bed into which the graft must be laid is often a hostile one and is densely scarred. Clawson and Seddon (1960) showed that if the sciatic nerve could be apposed with the knee in $90^{\circ}$ of flexion, and if splintage were sufficiently prolonged, worthwhile results could be obtained. The results of grafting long gaps in the common peroneal nerve are so poor that the appropriate muscle transfer is often the better option. The results of grafting of the tibial nerve are so often marred by pain that perhaps the best aim is a supple limb and the prevention of trophic changes, with the addition of a simple foot-drop splint if the sciatic trunk is irreparably damaged. When direct suture has been performed after resection of nerve tissue, the period of splintage and its serial release is of great importance. Repairs of the sciatic nerve need to be protected from full extension at the knee for a period of 12 weeks, and in the upper limb protection should be continued for a minimum of six weeks, although it is advisable to return the wrist to neutral at three weeks as the correction of flexion deformity here can be difficult.

Nerve grafting. In many cases there is no alternative to repair by grafting. Direct suture of lacerations of the brachial plexus or the nerve trunks in the arm is often impossible after a delay of a few days. Ruptures of nerve trunks following traction lesions invariably require grafting, as do wounds with extensive loss of soft tissue. Ischaemia or infection add to the extent of soft tissue injury and nerve grafting is usually indicated here too.

Although some success has been recorded using homografts (Seddon 1975), these are inferior to autografts. The sural nerve is the best of the available donor nerves since it is the longest and the resulting defect is relatively tolerable. The medial cutaneous nerve of the forearm is also useful, but it branches at the elbow and little more than $20 \mathrm{~cm}$ can be utilised. The superficial radial nerve may be important in providing sensation to 


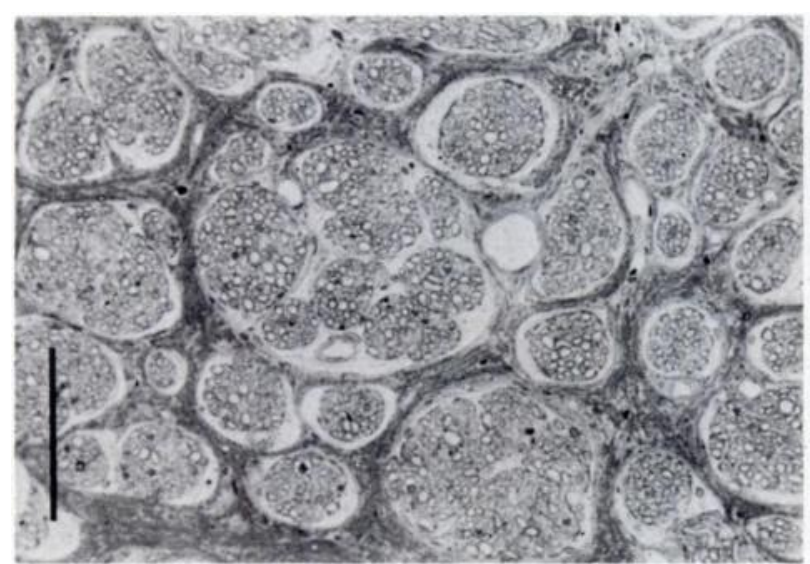

Fig. 1

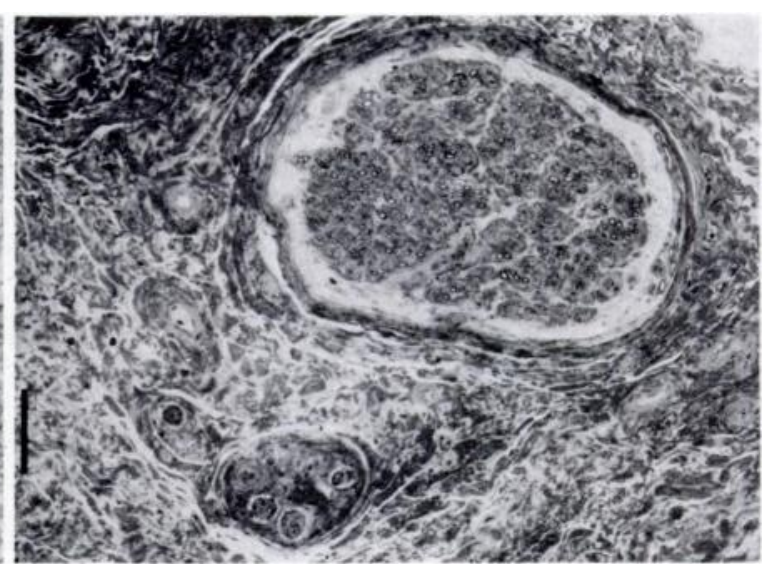

Fig. 2

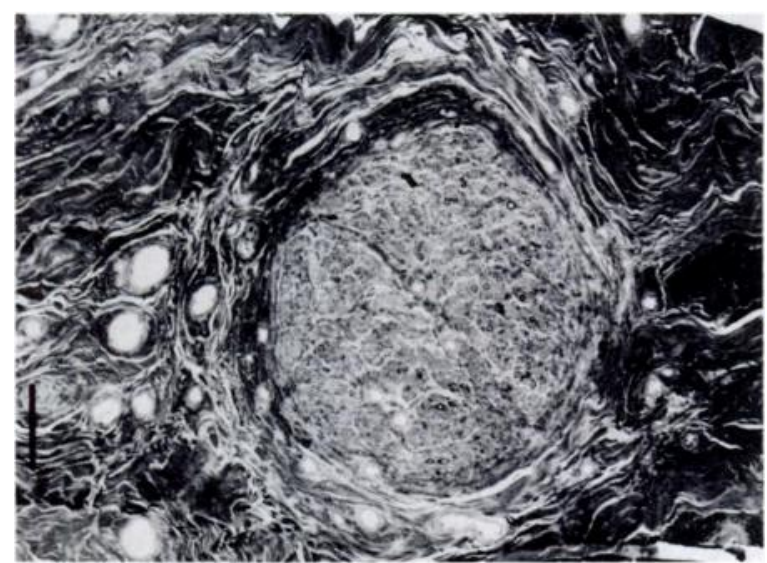

Fig. 3

These three illustrations are biopsies taken from a failed graft of a median nerve in the forearm performed three years previously. Figure 1 -Section at the proximal suture line, showing numerous regenerating units. Figure $2-$ Section through the middle of the graft shows increasing fibrosis and loss of neural elements. Figure 3 -Section through the distal segment of the graft: failure of regeneration becomes more evident. The black line in all three illustrations is a scale bar $(100 \mu \mathrm{m})$.

the hand. It branches frequently and, when injured, is too often a source of pain and hypersensitivity. It should be used rarely, if at all. The architecture of the nerve face of any cutaneous sensory nerve is very different from that of the larger nerve trunks; the bundles are smaller and there must inevitably be very considerable overlap of connective and neural tissue. If a long gap is to be bridged, the surgeon must accept that such is the change in the topography of individual axons in their passage down the nerve trunk that the task of matching proximal to distal stumps accurately is currently unachievable (Sunderland 1978). To survive, free nerve grafts must obtain their blood supply from the bed and it may be necessary to route nerve grafts circuitously across healthy muscle, or alternatively to excise scar tissue and apply a flap of muscle or skin in its place.

Although good results can be achieved after grafting of the median or ulnar nerves in the forearm and wrist (Millesi, Meissl and Berger 1972), failure is frequent
(Figs 1 to 3) and the reasons for this are not at all clear, although it seems that naked tendon or scar is a hostile medium for nerve regeneration.

St Clair Strange's development of the ulnar pedicle graft (1950) has proved to be of great value in cases where both median and ulnar nerves are destroyed in the forearm by ischaemia or extensive soft-tissue loss. When this technique is used in young children the neural deficit in the ulnar territory may ultimately be surprisingly slight (Brooks, personal communication). St Clair Strange emphasised the importance of maintaining a blood supply to the grafted nerve, and the logical extension of the free vascularised nerve graft was made by Taylor and Ham in 1976 who used the superficial radial nerve based on the radial artery in the treatment of a median nerve injury. Since then, other vascularised cutaneous nerve grafts have been described: the sural graft (Fig. 4) based either on the short saphenous vein (Jamieson and Eames 1980) or on its own artery (Gilbert 


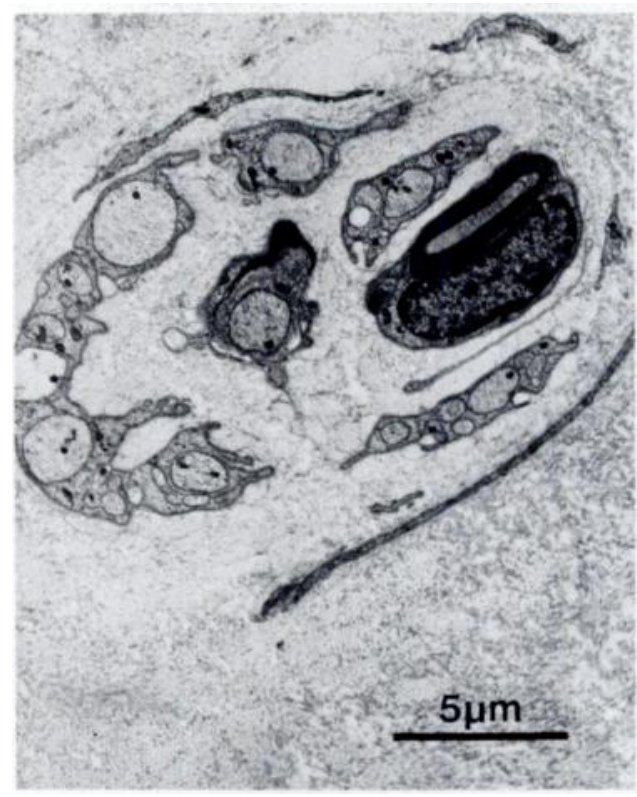

Fig. 4

Section from a vascularised sural nerve used to repair a long defect in the median nerve in the forearm 10 years after injury. This repair failed, as had a wellexecuted interfascicular graft performed nine years previously. The nerve graft was re-explored two years after the second operation: the vascular anastomosis was clearly intact. The appearance of the biopsy was similar in both cases, showing dense intraneural fibrosis with progressive loss of regenerating axons.

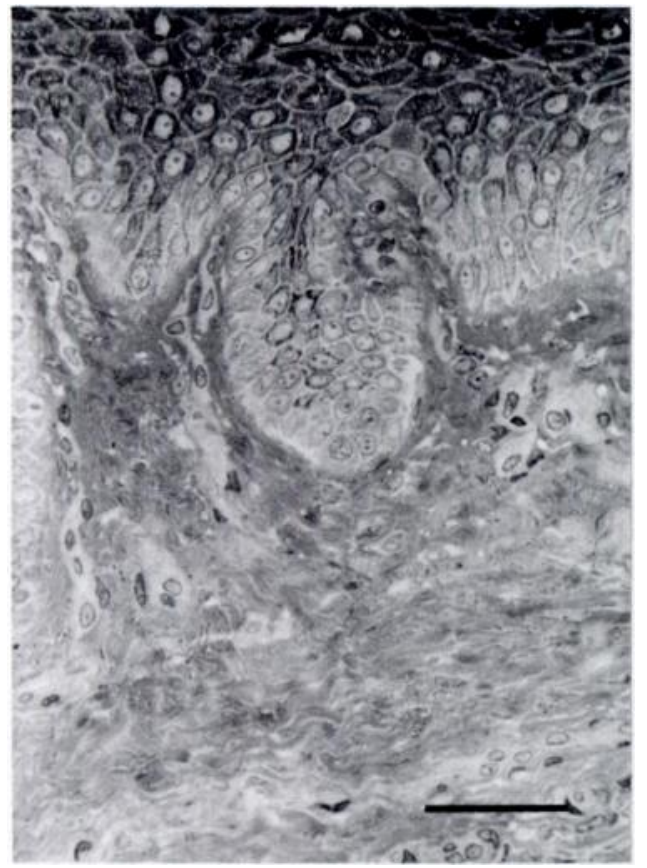

Fig. 5

A biopsy of a neurovascular island flap transferred from the ring to the index finger 10 years previously. The patient had noticed increasing impairment of sensation in the flap. The biopsy shows no recognisable Meissner`s corpuscles within the dermis (scale $\mathrm{bar}=50 \mu \mathrm{m})$.

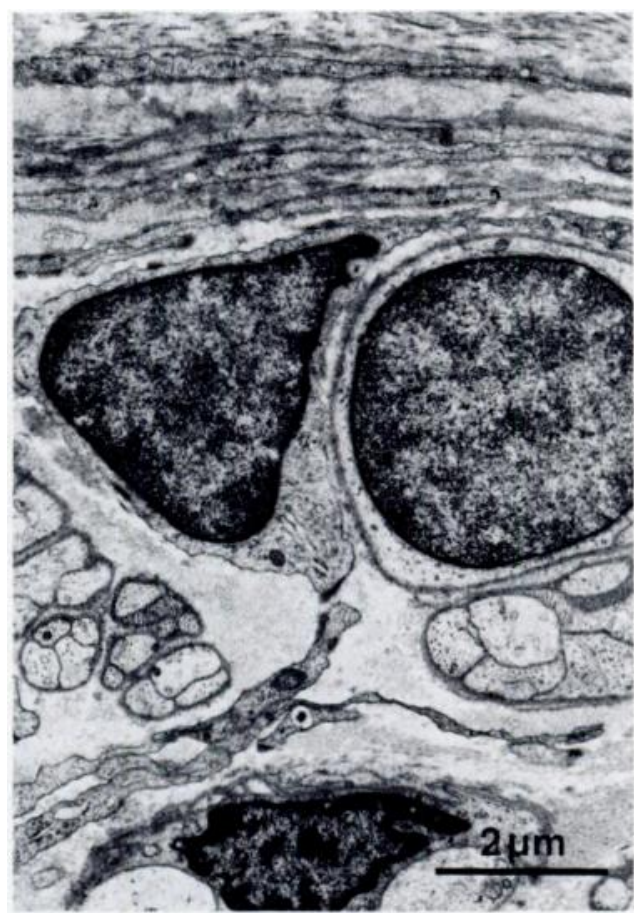

Fig. 6

A biopsy from the pulp of the index finger of a patient with complete transection and wide separation of the median nerve. The patient reported some return of sensation over the course of two years, and regenerating axons are seen close to the lamellae of a Meissner's corpuscle. A local anaesthetic block of the superficial radial nerve suggested that this was the source. 
1984), the medial cutaneous nerve of the forearm (Comtet et al. 1981) and the lateral cutaneous nerve of the thigh (Evans, personal communication). These slender vascularised nerve grafts, whose anatomy has been reviewed by Breidenbach and Terzis (1984), have not yet proved themselves in clinical practice.

For the repair of brachial plexus traction lesions where the prognosis for recovery of the ulnar nerve seemed hopeless, a free vascularised ulnar nerve graft was introduced in 1976 (Bonney et al. 1984); the results of this technique are more promising.

\section{Some special problems}

The median nerve. Restoration of sensation to the hand after median nerve injuries is difficult. Although protective sensation may return in some cases where repair is carried out years after injury of the nerve (Brooks, personal communication), such late repairs may fail or may be impossible. The neurovascular island flap transfer (Campbell Reid 1966) is a most ingenious and elegant way of restoring at least one of the "eyes" of the hand. However, over the course of time some of these flaps lose sensation, perhaps reflecting the impairment of overall function of the hand (Fig. 5).

Of the various techniques used to restore sensation in the median nerve territory, Strange's ulnar pedicle graft remains the most effective.

Partial injuries of nerves. Repair of these injuries, particularly those of the median nerve, are a particularly difficult problem; they are very often painful and when the injury is the result of a missile, true causalgia may develop. There is no doubt that these injuries are best treated at the earliest possible opportunity before scarring obliterates the architecture of the nerves. A striking feature in the exploration of these injuries is the extensive branching between individual bundles. This must cast a shadow on so-called interfascicular neurolysis in late cases; even when meticulously carried out, damage to conducting neural elements must often occur (Narakas 1978). To dissect between nerve bundles in the treatment of compression lesions of the nerves, as in the median nerve in the carpal tunnel, must be considered hazardous.

Assessment. Study of the course of recovery following repair of divided peripheral nerves demands accurate and precise observation and recording. There are many pitfalls, and neurophysiological examination may reveal unusual patterns of overlap or cross-innervation between the territories of nerve trunks. Return of protective sensation to the hand does not always represent success of a nerve repair, as this is sometimes seen in patients who prove to have division of the median nerve with wide separation of the nerve stumps (Fig. 6).

The localisation and functional assessment charts developed by Wynn Parry and Salter (1976) remain the most useful and accurate means of recording return of function during the period of observation.

\section{The brachial plexus}

Injuries of the brachial plexus are becoming more frequent, particularly closed traction injuries from motorcycle accidents. Diagnosis is difficult, and if open exploration is indicated to confirm diagnosis or to repair rupture of nerve trunks or of vessels, familiarity with the field is essential. There are considerable hazards at operation; sure knowledge of exposure and control of the great vessels at the root of the neck is a prerequisite. There are particular hazards when operation is carried out within a few days of injury; these include a rush of cerebrospinal fluid leading to coning of the medulla, air embolism, injury to the pleura or underlying lung, and complications from other, perhaps unrecognised, injuries.

Open wounds of the brachial plexus are treated by following the same principles as those applied to any other injury of a major nerve trunk. It is, unfortunately, necessary to state that the brachial plexus is not infrequently injured during the course of operations in the neck. Although our experience of missile injuries is limited, it seems that missiles cause ruptures of nerve roots or trunks in one-half of cases, that injury to the subclavian or axillary vessels is the rule rather than the exception, and that severe pain, either from partial severance of nerve trunks or from retention of a metal fragment is usual.

Post-irradiation neuritis of the brachial plexus is the commonest example of a nerve lesion from radiotherapy. Pain is usual; loss of sensation and of power is progressive and may lead to complete loss of function in the affected limb. The appearance of symptoms following radiotherapy may be delayed for a few months or for many years; their onset may be sudden with extreme pain or impairment which may be so slow that diagnosis of peripheral compression neuropathy may reasonably be entertained. It is often difficult to distinguish this condition from malignant infiltration of the plexus; pain is not confined to the latter and multiple open biopsies remain the only sure mode of confirming recurrence of tumour.

However, incisions through indurated and irradiated skin do not heal well; the transverse supraclavicular incision in the neck, combined with an approach through the axilla, offers the safest approach. External neurolysis of the brachial plexus by excision of scarred scalenus anterior, subclavius, and pectoralis minor muscles, with resection of the accessible epineurium usually relieves pain and is often effective in arresting progression of neural deficit; however, this technique improves the neural state in only a small minority of patients. The bold aim of revascularisation of the ischaemic nerve trunks, whether by transfer of free vascularised omentum or by a latissimus dorsi flap (Narakas 1984) has not resulted in significant improvement. Ultrastructural studies of biopsy specimens in severe cases show extensive and dense endoneural fibrosis, and it is difficult to 


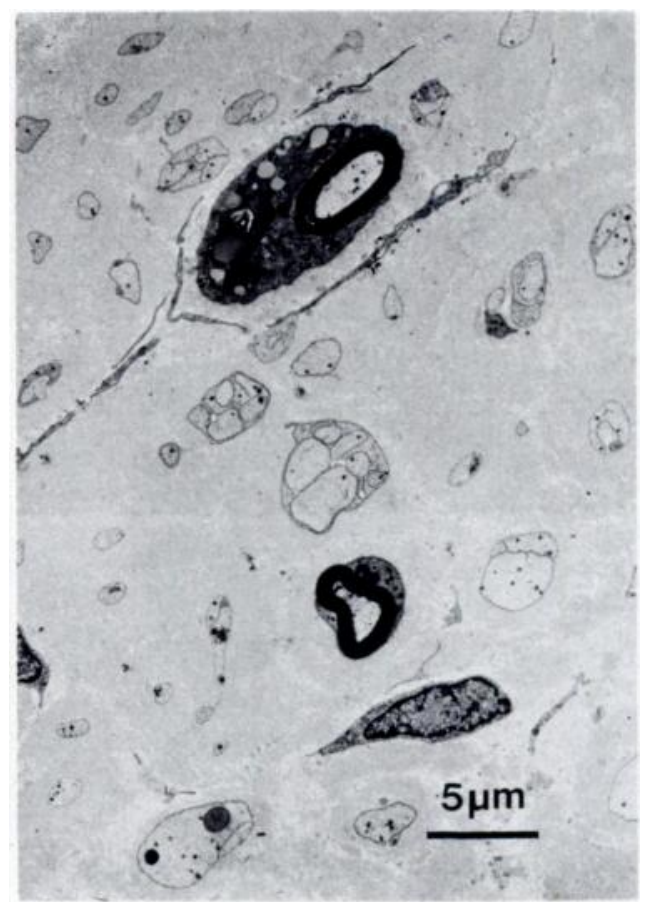

Fig. 7

Section from a biopsy of a bundle from the lateral cord in a patient with progressive neural impairment after radiotherapy to the axilla.

imagine any operation which can overcome this (Fig. 7).

Diagnosis in closed traction lesions, the most common variety. can be difficult. Bonney's concept of preand post-ganglionic injury (1954) is the foundation of our understanding of these injuries. Persistence of the normal triple response following intradermal injection of histamine in anaesthetic skin of the limb after about three weeks from injury is virtual proof of pre-ganglionic injury to the roots supplying that territory; the demonstration of nerve action potentials in the ulnar and median nerves after stimulation of the digits of the hand after the same time interval is further evidence (Bonney and Gilliatt 1958). Myelography is an invasive procedure and has its complications, but is an important adjunct where operative exploration is planned (Yeoman 1968); its accuracy has been considerably refined by combination with computerised tomography (Fig. 8).

All too often, the diagnosis of complete avulsion of the spinal nerves from the cord is clinically obvious. Complete paralysis of the upper limb with paralysis of the thoraco-scapular muscles, and anaesthesia of that limb with disturbance of sensation above the clavicle, suggest the worst case. There may be rupture of the subclavian vessels and a Bernard-Horner syndrome. The burning pain felt in the anaesthetic hand is a most important indication of severe injury to the lower two roots of the plexus. More than $40 \%$ of patients referred to St Mary's and the Royal National Orthopaedic Hospitals with brachial plexus injuries prove to have complete preganglionic lesions.
The indications for exploration in closed lesions are: to establish an accurate diagnosis and prognosis; to repair ruptures of nerve trunks; and to plan "reconstruction" of the limb by transfer of muscle or tendon or by provision of an orthosis before the patient becomes habitually onehanded. Exposure is much easier when conducted within a few days of injury, and it appears that the results of nerve grafting in these cases is better than in late cases. Associated vascular injuries are common and pose particular problems. Rupture of the subclavian vessels above the clavicle is usually associated with complete pre-ganglionic avulsion of all five roots of the brachial plexus: an urgent operation may be indicated to save the patient's life. Rupture of the vessels below the clavicle, an injury following hyperextension of the shoulder, is usually associated with rupture of individual nerve trunks, particularly suprascapular, axillary, radial, and musculocutaneous nerves. Failure to restore early and adequate perfusion dooms the limb as surely as in complete pre-ganglionic injury. The vascular injury is best treated with a reverse vein graft; the gap between healthy vessels may be long, and end-to-side anastomosis with interrupted sutures reduces the problem of disparity between the lumina as well as aiding the patency of anastomosis. If possible, any associated rupture of nerve trunks should be treated at the same time, as late exploration in these cases is difficult and unrewarding. Nerve grafts are always required and functional improvement can be expected following repair of musculocutaneous or axillary nerves, whereas recovery following 
repair of median or ulnar nerves is disappointing. Decompression of the brachial bundle and of the flexor muscles of the forearm is essential; gas gangrene has occurred in cases where this was not done.

Methods of repair. The mode of repair in lesions of the brachial plexus is dictated by the findings at operation. Direct suture is possible in stab wounds, but rarely so if exploration is delayed. Transfer of an avulsed root to a ruptured proximal stump is occasionally possible but the great majority of patients require nerve grafting. recommended for adults with complete lesions. The operation should be performed within six months of injury at the most, preferably within three, and a certain diagnosis of pre-ganglionic injury must be made.

The functional outcome of repairs of ruptures of the brachial plexus is limited. It is reasonable to anticipate a return of impaired control of the shoulder joint and of worthwhile flexion of the elbow after repair of the fifth and sixth cervical nerves, and of protective sensation in the hand with flexion of the wrist and digits after grafts

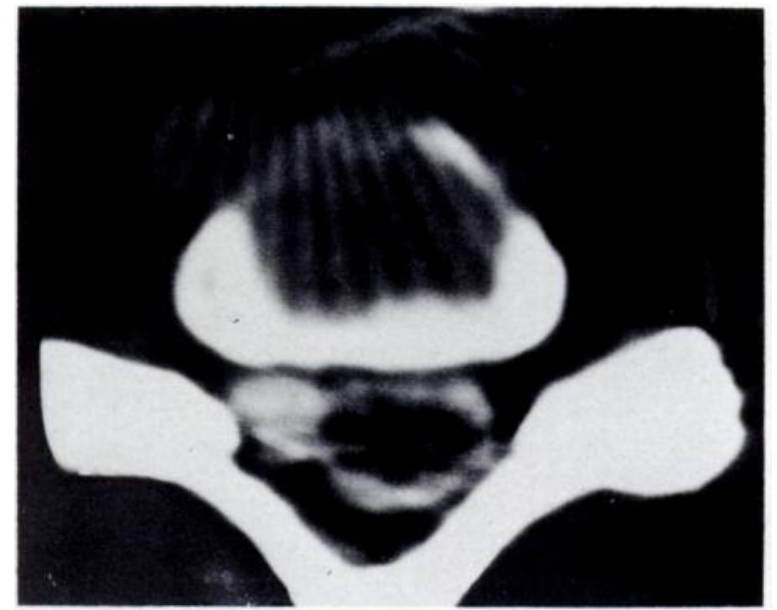

Fig. 8

Computerised tomography with dilute radio-opaque medium demonstrates an intradural tear of the sixth cervical root: this was not apparent at operation. (Courtesy of Dr David Sutton. former Head of Department of Radiology. St Mary’s Hospital, London.)
Isolated ruptures of the fifth, sixth or seventh cervical nerves, or of ruptures at the level of the trunk or the cord, require cutaneous nerve grafts. If pre-ganglionic injury to the eighth cervical and the first thoracic roots is confirmed, then the ulnar nerve can be used, either a free vascularised graft based on the ulnar artery or on the ulnar collateral vessels, or the most proximal segment of the ulnar nerve may be swung up as a pedicle graft based on the superior ulnar collateral vessels. In cases of complete avulson of the brachial plexus from the spinal cord. intercostal nerve transfer offers the possibility of restoring limited function to the limb. This technique was first used by Yeoman and Seddon (Seddon 1975); Narakas (1978) has reviewed the matter fully. This extensive procedure can be considered in children and in adults with irreparable lesions of the fifth, sixth and seventh cervical nerves but with some recovery down the lower trunk. The functional outcome is so limited that it can rarely be to the lower trunk or median nerve. However, the number of adults with worthwhile recovery into the hand following the most extensive repairs of the brachial plexus is very limited. As might be expected, children do much better.

A most important aspect of the treatment of nerve injuries, particularly those affecting the brachial plexus, is rehabilitation; that is, the restoration of maximum function to the limb by the relief of pain, by appropriate splintage, and by tendon or muscle transfer or stabilising operations. Re-training for another occupation may be necessary. It is plain that the need for establishing units with skilled clinicians and facilities to treat these injuries is as great now as when peripheral nerve injury units were established during the Second World War.

I express my thanks to $\mathrm{Mr}$ Stephen Griffiths, at the Institute of Orthopaedics, Royal National Orthopaedic Hospital, who prepared the histological specimens and the photography for this article. 


\title{
IATROGENIC INJURIES OF NERVES
}

\author{
George Bonney
}

I should put "iatrogenic" in inverted commas because I am uncertain of its derivation: I feel that it means "doctor-producing" rather than "produced by a doctor", and in that feeling I am supported by the use of terms such as "osteogenic" and "carcinogenic". It has, however, been pointed out to me by a classical scholar of distinction that the term "parthenogenesis" implies "arising from a virgin" rather than "virgin producing". I continue to believe that if we wish to imply a lesion produced by a doctor we should use the term "iatrogenous", but I am content to leave the matter for debate among Wykehamists.

This article deals only with lesions of nervous tissue outside the brain and spinal cord, though it is as well to remind readers of the particular sensitivity of the tissues within the skull and spinal canal: handling which might be tolerated by a peripheral nerve could produce an irrecoverable lesion in the brain or spinal cord.

It is not only surgeons who may injure peripheral nerves: doctors in most specialties are from time to time responsible for such damage. The physician who chooses to give drugs by injection rather than by mouth may choose a site for injection too near the radial or the sciatic nerve. The anaesthetist may inject thiopentone into or around the median nerve; epidural injection of lignocaine or bupivacaine may lead to permanent damage to the cauda equina. Even the radiologist can produce severe effects by the injection of contrast medium into the great vessels or into the subarachnoid space. Happily, the likelihood of such mischances is being steadily reduced by advances in diagnostic imaging techniques.

In the past radiotherapists also have been responsible for damage, the consequences of which have become apparent only in the last few years. In particular, irradiation for breast cancer has led to neuropathy in a number of women. Symptoms may appear within months of treatment, or their onset may be delayed for as long as 20 years. The condition is slow, painful and disabling; its response to treatment is unpredictable; its occurrence seems to be to some extent dependent on the amount of radiation. Certainly some women seem to be much more sensitive than others to radiation.

The reduction of the coagulability of the blood, undertaken for prevention of thrombosis or for its treatment, may lead to bleeding into a nerve; this is more commonly seen when heparin is used than when warfarin or other coumarins are used, perhaps because reduction of coagulability is so often imperfectly achieved when the latter group of drugs is used. The onset of symptoms is sudden: the patient complains of pain in the distribution of the nerve followed shortly by paralysis. The paralysis is deep and complete - so much so that not only motor and sensory modalities are affected but also vasomotor and sudomotor functions. There may even be blistering of the digits whose skin is supplied by the affected nerve. The author has seen this phenomenon in the case of the median and sciatic nerves: perhaps these nerves, with their strong axial blood supply, are more susceptible to such lesions than are nerves with larger contribution from a segmental blood supply.

It is of course the surgeon who, with the help of the anaesthetist, is most commonly responsible for serious damage to nerves. The categories of such "surgical" damage are perhaps as follows: direct damage by knife or other cutting instruments, inflicted either deliberately or in error; accidental damage by agents other than the knife or by persons other than the surgeon, during an operation, in the field of the operation; accidental damage by traction or by pressure during the period of an operation, not in the field of the operation; ischaemic damage caused by interference with a main vessel or as part of a compartment syndrome; damage by a tourniquet; and birth injuries.

Damage severe enough to be apparent clinically is, of course, more likely to be produced in patients whose nerves are abnormally susceptible, and in whom a proportion of the conducting tissue may have ceased to function before the damage occurred. Such patients are diabetics, alcoholics, patients affected by rheumatoid arthritis, patients who have over a short period lost much weight or patients with carcinomatous neuropathy. These are the common instances but many other neuropathies may contribute to the liability to damage.

Direct damage. It is plain that if a surgeon is operating for malignant disease and finds that a section of a main nerve runs through the tumour, he is justified in removing a length of that nerve. It is less forgivable to resect a length of nerve when operating on a neurilemmoma, a tumour which can usually be enucleated without important damage to conducting elements. Examples of this mistake are seen most often in the upper trunk of the brachial plexus. The "lump" may be thought to be an enlarged node and the operation may be entrusted to a surgeon of limited experience; the part of the trunk affected may be resected without the surgeon being aware of the nature of the damage inflicted. Similar instances have been seen in the median nerve or the common peroneal nerve (when removing a ganglion), or in the radial nerve in the axilla (when removing an enlarged axillary lymph node). Hardly forgivable is the division of 
R. BIRCH, G. BONNEY, J. PAYAN, C. B. WYNN PARRY, A. IGGO

the accessory nerve during biopsy of a lymph node in the posterior triangle of the neck, where the nerve lies very superficially and is liable to damage as soon as the skin has been incised.

Surgeons have been known to cut the upper trunk of the brachial plexus during cervical sympathectomy, mistaking it for the scalenus anterior muscle. During similar operations other surgeons have divided the first thoracic nerve, mistaking it for the ganglionated sympathetic chain. Similarly, division of the white ramus of the first thoracic nerve can occur during sympathectomy for hyperhidrosis: a Bernard-Horner syndrome is an affliction for a young girl. Even the transaxillary route to the sympathetic chain can be complicated by division of the nerve to the serratus anterior muscle.

The musculocutaneous nerve penetrates the coracobrachialis muscle and emerges in whole or in part from the lateral aspect of this muscle, sometimes less than $2.5 \mathrm{~cm}$ below the coracoid process. It is at risk during most operations for recurrent anterior dislocation of the shoulder, especially those involving division of the coracoid process and mobilisation of the coracobrachialis muscle and the short head of the biceps muscle.

Sometimes an inexperienced surgeon will mistake the median nerve for a tendon: when the tendon of palmaris longus muscle was in common use as a graft for a cut flexor tendon, lengths of median nerve were from time to time taken as "tendon grafts". Even injury to an apparently trivial nerve may produce important consequences: damage to the superficial branch of the radial nerve at the wrist (which may occur during operations for stenosing tenovaginitis) may cause severe and persistent pain and hyperaesthesia in the distribution of the nerve.

The radial nerve, in its relationship to the humeral shaft, is in great danger, as is its continuation, the posterior interosseous nerve, in its course in relation to the head and neck of the radius. The attention of surgeons dealing with fractures is drawn to these nerves; a plate may be fixed over the radial nerve, or the posterior interosseous nerve may be cut when the head of the radius is removed. Digital nerves are not, of course, immune from damage during operations for Dupuytren's disease; the difficulty of avoiding one is sometimes so great that the damage seems excusable.

The sciatic nerve may (though rarely) be divided during removal of an intramedullary nail or during replacement arthroplasty of the hip; and operations for varicose veins yield a steady harvest of lesions of the common peroneal nerve, in addition to the more serious damage caused by "stripping" the femoral artery in mistake for the long saphenous vein. The common peroneal nerve is also at risk during operations involving division of the neck of the fibula or removal of its head.

Most of the injuries described above are those inflicted by plastic or orthopaedic surgeons. Abdominal surgeons rarely encounter peripheral nerves, but from time to time the right femoral nerve is injured in its abdominal portion during removal of the appendix, and either nerve may be injured during iliofemoral by-pass operations.

Damage by pressure or by traction during operation. It is virtually impossible to measure the amount of traction or pressure applied to a nerve during the retractions necessary during most operations. The nerves most commonly at risk are the sciatic, the brachial plexus above and below the clavicle, the common peroneal and the femoral. The first and the last are at risk during arthroplasty of the hip; possible causes are traction as a result of the insertion of an over-long femoral component; direct pressure from a retractor or elevator; possibly the heat of hardening cement; and, very occasionally, direct pressure from the inclusion of the sciatic nerve when reattaching the greater trochanter. Sometimes, in repeat operations, nerves may be so buried in scar tissue that they are injured in error and the damage is unknown to the surgeon. The sciatic nerve is affected more often than the femoral; Harris (1983) indicates that, as judged by clinical manifestations, "neuropathy" occurs in less than $1 \%$ of arthroplasties. However, he quotes Weber, Daube and Coventry (1976) as having found electromyographic evidence of a lesion in most patients after hip replacement, though overt clinical manifestations are rare. The lesion may be partial or complete and usually the common peroneal component is affected more deeply than the tibial; the depth ranges from a recoverable conduction block (neurapraxia) to an irrecoverable neurotmesis, between which extremes all depths of lesion occur. In any case, with a lesion at this level, recovery is commonly imperfect.

The brachial plexus above the clavicle may be damaged by traction during sympathectomy, and during the removal of a large seventh cervical rib or of the first rib. Below the clavicle it may be damaged by pressure during a transaxillary approach to the shoulder, to the first rib, or to the sympathetic chain. In such circumstances the lesion may initially be deep, but it is usually only a conduction block. Elevators put round the humerus may cause an unacceptable degree of pressure or traction on the radial nerve. Even the sciatic nerve is not immune from pressure caused by an elevator placed behind the upper end of the femur during the performance of a trochanteric osteotomy. Removing a central nuclear protrusion of a lumbar intervertebral disc by the epidural route through an interlaminar approach (in the author's view an unacceptable method) may lead to pressure on the cauda equina, causing severe and irreversible damage to one or more of its component nerves.

Ischaemic damage. The blood supply to a limb may be cut off or reduced to an unacceptable level by interruption of a main vessel or by pressure within the fascial compartments of a limb. Delay in recognising and treating damage to the brachial or common femoral artery is sufficient to impair or even destroy the function of the 
peripheral nerves of the limb. In such instances it is not always sufficient to restore the main blood supply: the fasciae enclosing the compartment should be slit. Signs of nerve damage are indeed one of the earliest and most important signs of a compartment syndrome: loss or impairment of sensibility of the toes within 24 hours of a tibial fracture is an indication for instant and decisive action.

Tourniquet damage. This matter has been dealt with very fully by Aho et al. (1983). It is enough to note here that the application of a tourniquet cuff at or above systolic pressure and its retention for more than 20 minutes always produces a nerve lesion; this fact can be tested by the clinician. The lesion nearly always recovers before the patient regains consciousness but in the following circumstances it may persist: when the cuff is too narrow; when it has been at too high a pressure for too long; when it has been applied for too long to a very thin limb; when it has been applied for too long to the limb of a patient whose nerves are unduly susceptible to pressure; when the cuff has been wrongly placed; or when (very rare nowadays) the cuff has been left inflated after the end of the operation. Sometimes the lesion is a neurapraxia, sometimes it is deeper and takes correspondingly longer to recover, and sometimes it does not recover at all.

Pressure or traction during anaesthesia. It is common for a patient regaining consciousness after anaesthesia to notice that the little and ring fingers of one hand feel numb; later, a functional defect of the hand is noticed. The ulnar nerve may have been damaged, either by direct pressure in the region of the medial epicondyle or by constriction under the arch of origin of the flexor carpi ulnaris muscle. Wadsworth in particular has drawn attention to this lesion, to its method of production and to the steps necessary to avoid its occurrence (Wadsworth 1977; Wadsworth and Brooks 1982). Other nerves of the upper limb may be damaged similarly. Thus, the position of abduction at the shoulder is clearly one of danger for the brachial plexus: the upper part of the plexus may be compressed by the rising clavicle while the lower part may be stretched over the head of the humerus. The use of shoulder rests has now more or less been abandoned, but it was a common and potent cause of damage to the plexus during gynaecological operations (Bonney 1947).

The nerves of the lower limb are less susceptible, but the common peroneal nerve in its relation to the head and neck of the fibula is vulnerable, especially in thin patients.

Other injuries. The recurrent laryngeal nerve may be damaged during operation for cervical fusion by the anterior route and the hypoglossal nerve in high cervical fusion by that route.

This is hardly the place in which to open the great subject of damage to nerves (most commonly the brachial plexus) during delivery. In spite of improvements in antenatal care and increased skill in the delivery room, such lesions still occur and vary in extent and degree from conduction block to avulsion of nerve roots from the spinal cord.

\section{Diagnosis and treatment}

Diagnosis of a lesion produced in any of the ways listed above differs in no way from the diagnosis of any other nerve lesion. It is, however, always hard for the operating surgeon to credit that he has been responsible for the production of a serious nerve lesion, a feeling which may cloud vision and inhibit action. The site of the lesion has to be determined by reference to the area affected, its extent by whether paralysis is complete or partial and its depth by the extent and the degree to which all modalities of conduction are affected. The presence of an irritative lesion-for instance, one caused by inclusion of a nerve in a suture-is usually indicated by persistent pain or other paraesthesia. After a few days, examination of nerve conduction and of the electrical responses of muscles is useful, and later, in special cases, a CT scan with enhancement assists diagnosis.

If there is an incision over the line of a main nerve and if, after operation, there is complete paralysis (including vasomotor and sudomotor paralysis) in the distribution of that nerve, speculation is unnecessary: the nerve has been cut, and there will be no recovery unless it is explored and repaired. And, when pressure on a nerve has been followed by partial paralysis in its distribution, but stimulation below the level of the lesion produces a motor response, it is reasonable to assume that there has been a conduction block which will recover. Between these extremes, precise diagnosis is much more difficult. In one particular instance it was the completeness of a sciatic nerve lesion and the symptoms of an irritative lesion which led the surgeon to explore the nerve very soon after a hip arthroplasty; he found that the nerve had been included in the wire suture. However, in most cases of damage to the sciatic nerve during arthroplasty the paralysis is partial, and often the patient is old and unfit; in such circumstances only the boldest surgeon will press the matter to re-exploration.

In the author's view, the tendency should be towards exploration in open lesions, and to observation in closed lesions. However, with a sciatic nerve lesion after a hip operation, the distance of the lesion (and in particular of the common peroneal component) from the nearest point of innervation is so great that, with a deep lesion, early operation should be seriously contemplated. It is also debatable whether deep lesions of the ulnar nerve after anaesthesia should not be treated by early decompression. It is hardly necessary to stress that the best results after suture are obtained when the repair is done soon after injury. Epineurotomy should particularly be considered when injection of an irritant close to a nerve has damaged it.

The most important lesson to be learned from all the 
examples quoted is that of avoidance. Very accurate knowledge of anatomy is necessary for the surgeon operating in places of special hazard, such as the root of the neck. (It will be recalled that this was the site that, according to Homer, Achilles chose for the spearthrust that despatched Hector of the glancing helm.) Particular difficulty is introduced by scarring resulting from wounding, infection, or a previous intervention. In some cases-such as that of the facial nerve--the conducting tissue is so intimately related to other tissues that separation by naked-eye dissection may not be sufficient to avoid damage. In such cases, it is as well for the anaesthetist to avoid the use of muscle relaxants or to reverse their action before the nerve dissection is begun; electrical stimulation can then be used to determine what is and what is not conducting tissue. The surgeon may find it best to use a loupe or even a microscope. These techniques may be so refined as to permit the identification of the white ramus from the first thoracic nerve: as the ramus is stimulated the pupil of the ipsilateral eye can be seen to dilate.

When surgery involves retracting conducting tissue, the assistants should be instructed to retract gently and to cease retraction when the surgeon is not actually working in that field. Exposed nerves should be held out of the way with lightly-weighted plastic slings and should be kept moist. When the brachial plexus is being retracted and the shoulder abducted during transaxillary removal of the first rib, the plexus, the surgeon and the assistant should all be given five minutes' rest every 15 minutes. If the surgeon is uncertain of the nature of a nerve-occupying tumour, the wound should be closed and the patient sent to a surgeon with particular experience of work on nerves and nerve-occupying tumours.

Vulnerable nerves should be protected carefully while the patient is unconscious: the elbows should be wrapped in Gamgee tissue; the backs of the knees should be padded adequately; and the upper limbs should be positioned so that the patient does not compress or stretch the brachial plexus while unconscious. Ischaemia should be recognised and treated immediately. Recorded pressures within tourniquet cuffs should be monitored regularly by comparison with a mercury manometer. Tourniquet times should be adjusted to the state of the limb and of the patient; they should always be recorded. Birth injuries of the brachial plexus have received inadequate attention in this country, and it is very likely that a more systematic and more constructive approach would lead to important advances.

\section{Legal aspects}

When a patient enters hospital without a nerve lesion and emerges with one, it is seldom possible to resist an allegation of negligence. Reliance is sometimes placed on the recorded fact that a certain operation-for instance, hip arthroplasty - carries a known incidence of lesions of the sciatic nerve. In some cases, in which no error in pro- cedure can be detected, it is possible to sustain this defence. However, when such cases are examined in detail, an error is commonly perceived and under such circumstances resistance is usually in vain. It may indeed be argued that because there is a published incidence of a certain complication associated with a certain operation, the surgeon should be specially on guard to avoid it, and the patient should be warned specifically about its possibility before giving consent to the operation. When a major nerve has been cut in error or when there has been delay in the recognition and treatment of ischaemia, successful defence is rarely possible. Birth injuries of peripheral nerves do not seem to attract much litigation, though brain damage in the newborn is a constant subject for legal action.

Res ipsa loquitur (the matter speaks for itself) is among phrases long used by lawyers to confuse and intimidate defendants. Its application is important to clinicians, for it implies that if, while under treatment, a patient suffers (exempli gratia) a nerve lesion, it is for the clinician to offer an explanation of non-negligent causation. If such an explanation is not forthcoming, negligence will be presumed.

All practising doctors know that the past 20 years have seen an enormous increase in the number of cases of alleged negligence against doctors. It is hard to know whether there has in fact been an increase in the incidence of negligence, or whether the standards by which doctors are judged have risen, or whether instances of negligence previously hidden by the enormous cost of legal action are now being revealed. Possibly, too, patients trust their doctors less than formerly. However, the fact is that over this period indemnity payments have vastly increased. In order to keep pace with this increase, the subscriptions of the defence organisations have increased enormously. No surgeon can work properly with the possibility of litigation constantly in mind. He should think carefully about each case, act carefully within his competence, share-as far as is possible-his thoughts with the patient, and make sure that the patient is warned of possible dangers. The extent and depth of this warning must, of course, be adjusted to take account of the patient's personality and capacity for comprehension. Clearly it is impossible to warn all patients of all possible complications; even to be half understood is a considerable achievement.

The keeping of clear records is always of great help to a doctor's advisers: imprecise phrases should be avoided and, in the case of nerve lesions, the exact nature and extent of the lesion as initially observed should always be recorded. It is unwise for a consultant surgeon to delegate to a junior the performance of an operation of known difficulty. It is possible that the junior may be better than the surgeon at the performance of that operation; but when the complication occurs, even though it was probably unavoidable, it is better that the consultant should be there to shoulder the responsibility. 
Wilfred Trotter, one of the greatest surgeons produced by this or by any other country, said that "an occupation for adults should . . . be subject to the tonic of difficulty and the spice of danger", and went on to say that he thought the practice of medicine dangerous "because it is so meagrely cared for by legal privilege and immunity ..." (Trotter 1941). It is related that Trotter accepted appointment to the council of one of the defence organisations, and that what he heard at the first meeting he attended so shocked him that he at once resigned. Evidently, medical negligence is no new thing; it is only when we use constant care and attention-and not always even then-that we can hope to escape the attentions of the lawyers.

\section{AN ELECTROMYOGRAPHER'S VIEW OF THE ULNAR NERVE}

\section{J. Payan}

Disorders of the ulnar nerve are of daily concern to the clinical electromyographer, challenging his ingenuity and inviting his participation in management. The value of his contribution depends upon the care with which deceptively simple techniques are used and the common sense and experience, particularly of normal variation, with which his results are interpreted. The services of an inadequate electromyographer are more dangerous than none at all.

Some diagnostic problems. The commonest difficulty, especially where medical services are readily available and patients present early, is that of assessing the significance of relatively minor sensory symptoms. This was often impossible until the advent, some twenty years ago, of commercially available equipment for measuring very small sensory responses in nerves. Patients are referred because ulnar paraesthesiae which had been negligible or intermittent have become more troublesome or persistent, making it necessary to distinguish between an isolated nerve lesion and the first expression of a subclinical polyneuropathy. Cases of diabetes not infrequently come to light in this way. Another common question is whether sensory symptoms in the ulnar distribution (which, it is sometimes forgotten, does not include the medial border of the forearm) are due to a lesion at elbow, plexus (for example a cervical rib or infiltration) or cervical spine.

The causes of weakness and wasting of small hand muscles are legion, and are not invariably identified by clinical examination alone. Early motor neurone disease is a well-known trap and is sometimes indistinguishable from lesions of the ulnar nerve in the palm without the aid of electromyography. A new source of confusion has arisen with the need to split the sternum for certain cardiac operations: stretching of the lower brachial plexus leads to symptoms and signs which may then be attributed to yet another iatrogenic lesion, namely compression of the ulnar nerve at the elbow under general anaesthesia.

Injury to the nerve by laceration is usually all too evident, but electromyography may demonstrate survival of some fibres in a lesion thought to be complete.
Similarly, when suture or graft seems to have failed it is sometimes possible to tell the surgeon that axonal sprouts are, after all, beginning to reach their destination in muscle. Electromyography may, unfortunately, also reveal that apparent improvement is due to the acquisition of trick movements.

\section{What does the electromyographer do?}

1. He stimulates nerves electrically and records the responses (potentials) evoked in sensory fibres, mixed nerve trunks and muscles. In the case of the ulnar nerve he measures sensory potentials at the wrist and on the dorsum of the hand when stimulating the little finger and the main nerve trunk respectively. The potential recorded in the cubital sulcus (or the axilla) on stimulating the nerve trunk distally is useful in almost every case, and the change in size or shape of the muscle potential when stimulating the nerve trunk at different sites may provide conclusive evidence of conduction block. Measurements of conduction velocity are in practice less valuable than is often believed, but the interval between stimulus and muscle response (motor latency) can be invaluable in two situations: when small hand muscles have atrophied completely and a delay in conduction to flexor carpi ulnaris confirms that the lesion is at the elbow, and when delay in conduction to the first dorsal interosseous muscle confirms the presence of a deep palmar lesion.

2. He puts needle electrodes into muscles, in the present context mainly the first dorsal interosseous muscle, the hypothenar group and the flexor carpi ulnaris, to detect denervation, fall-out of motor units and evidence of regeneration.

In experienced hands the investigation is usually no more than briefly uncomfortable, women being almost invariably more tolerant than men. The report should say not only whether there is an ulnar lesion, but where it is, how severe it is, whether it is isolated, whether demyelination or axonal degeneration is predominant and, if possible, whether it is getting worse. The conclusions the electromyographer draws from his investigation should 
be framed in a positive and constructive way that makes for logical and consistent management.

\section{The electromyographer's contribution to management}

The mildest case. When the only complaint is of intermittent sensory disturbance and there is no electromyographic abnormality, transient local nerve ischaemia may be assumed and advice given to avoid unnecessary, prolonged or repetitive elbow-bending. Should the sensory potential at the wrist on stimulating the little finger, and the mixed nerve potential at the elbow on stimulating at the wrist be of reduced amplitude some degree of structural damage to the nerve at the elbow is likely to be present, though perhaps to a scarcely greater degree than occurs in many of us, especially in manual workers, on the dominant side. While it is desirable to establish a quantitative baseline even at this early stage, to make subsequent detection of deterioration easier, the need for accurate evidence as to site, pathology, severity and progression is much greater when there is muscular weakness.

Acute weakness. When weakness of recent onset is complained of, electromyography may establish that there is a partial block of conduction at the elbow analogous to Saturday night palsy of the radial nerve. If stimulation of the nerve distal to the lesion results in normal hand muscle potentials and there is no evidence of denervation, full recovery should occur spontaneously. Because axonal degeneration takes some days to manifest itself electrophysiologically, however, the prognostic value of the test will be greater if it is performed at least a fortnight after the onset of weakness.

Chronic weakness, with or without intractable sensory symptoms. The site of the lesion. When symptoms of ulnar nerve damage have developed gradually over an uncertain period the question of surgery will arise, and with it the need for accurate localisation. Most lesions occur in the elbow region, and when this is not evident clinically it can nearly always be established electromyographically. More difficult, and all but impossible in the fat arm, is the distinction between the cubital sulcus and the fibrous bridge joining the two heads of origin of flexor carpi ulnaris. This is a pity, because it is a distinction which is, or should be, of some importance in reaching a decision as to the best operation to perform. Most lesions not at the elbow are at the wrist or in the palm, where both clinical and electromyographic identification of the site rest upon the precise distribution and severity of intrinsic muscle weakness and the presence or absence of sensory impairment. A particularly useful indication that weakness in the hand is due to a lesion at the wrist or in the palm is the demonstration of a normal sensory potential on the dorsum of the ulnar part of the hand. While adequate electromyographic investigation should rarely, if ever, fail to identify a distal lesion, certain localisation to the elbow is not always possible. The reason for this failure is usually inexplicable, and when it occurs there is no alternative to reliance upon clinical judgement.

The indications for operation. It is generally accepted that when a lesion has developed insidiously as a result of elbow deformity or of recurrent subluxation of the nerve, there is nothing to be gained by waiting for spontaneous recovery. This is surely also true when deterioration occurs in the absence of an obvious cause. When it is not certain that the condition is worsening because, as occasionally happens, the patient seems quite unaware that his hand muscles are wasting or because the doctor has not been acquainted with the problem for long enough to be sure, electromyography is invaluable. Serial investigations will provide incontrovertible evidence that the degree of damage is increasing, decreasing or remaining static. From this last possibility arises a further important and often very difficult question: how long is it justifiable to observe an apparently non-progressive lesion when there is motor involvement? The answer depends to a large extent on the cause of the lesion and the age of the patient.

Most surgeons, indeed most physicians, will be reluctant to wait long for spontaneous improvement in a young or middle-aged patient with even mild weakness and wasting if there is no history of an episode of compression or of avoidable occupational trauma. Electromyographic research has confirmed what common sense predicts, that even the very severe ulnar nerve lesion caused by inadvertent compression under general anaesthesia does no better after being operated upon than if left alone to recover, indeed sometimes does worse. For the same reason, namely that the pre-morbid relation of the nerve to its bed was satisfactory, a lesion caused by avoidable occupational trauma usually improves spontaneously when the nerve is treated with consideration. A rare exception to the last statement is the secondary ganglion said to form in the palm in response to repeated occupational trauma. Factors such as the age, occupation and temperament of the patient play their part in this as in other surgical decisions. Slight and apparently non-progressive wasting and weakness without troublesome sensory symptoms in the non-dominant hand of an old-age pensioner should not, as a rule, arouse surgical enthusiasm.

There remain the patients of any age, and with whatever history, in whom clinical examination reveals very severe wasting of ulnar-innervated small hand muscles and electromyography total denervation. If the lesion can be shown to lie at the elbow there is then no point in operation unless sensory symptoms demand relief.

Surgery and its complications. The electromyographer is bound to ruminate on the subject of operative technique because the failures eventually arrive at his door. The most popular operation, anterior transposition, gives rise to a far from negligible morbidity in the form of painful paraesthesiae and sometimes exquisite tenderness in the 
region of the scar, symptoms which may be regarded by the patient as worse than those which first brought him to the surgeon's attention. The view is sometimes encountered, implied by action if not expressed in words, that this is a relatively easy operation which can safely be left to unsupervised junior colleagues. The hopelessly disadvantageous position in which too many nerves are found a year after operation makes it difficult for the electromyographer to agree. The cause of the unpleasant symptoms is disputed, but inadvertent damage to the medial cutaneous nerve of the forearm is sometimes blamed. There has been much interest in recent years in putative mechanisms such as spontaneous impulse generation in immature nerve sprouts, increased sensitivity of central sensory neurones to normally sub-threshold peripheral stimuli, and "cross-talk" at the site of injury from large-diameter, low-threshold fibres to small calibre, high-threshold pain afferents. These speculations are of little interest to the patient, who is simply distressed that an operation expected to improve a situation has left it immeasurably worse.

When a lesion at the elbow has developed spontaneously and insidiously and nerve conduction studies suggest that compression is occurring at the level of the fibrous aponeurosis, it would seem eminently reasonable simply to expose and decompress the nerve. Nothing is to be lost thereby, and the option of eventual transposition remains. Other operations in current use are medial epicondylectomy and inter-fascicular neurolysis. The author has experience of neither, but electromyographic investigation in Denmark suggests that the latter operation, at least, is ill-advised (W. Trojaborg-personal communication).

The response to successful operation can be highly gratifying, and subjective improvement can begin almost at once, certainly long before electromyographic improvement is demonstrable.

Conclusion. The great surgeon to whom we owe the invaluable concept of neurapraxia, the late Sir Herbert Seddon, once wrote that no branch of medicine is more closely allied to orthopaedics than neurology. The role of the electromyographer is to extend the clinical examination of the peripheral nervous system. Perhaps nowhere does co-operation between surgeon and electromyographer hold out better prospect for the patient than in the field of ulnar nerve lesions, and the foregoing discussion will have served its purpose if it causes those who still refer their patients with the unthinking message, "? ulnar lesion. Please confirm before transposition", to ponder the implications of their words.

\section{SENSATION}

\section{B. Wynn Parry}

Despite the increased attention paid to the importance of skilled hand surgery since World War II, the results of peripheral nerve repair are still disappointing, particularly regarding sensory function. Thus, after repair of the median nerve in the adult, return of protective sensation may be expected but significant stereognostic function is the exception rather than the rule. Why is this so? One reason may be that the surgeon's expectations are low, for the assessment of sensation is traditionally by the two-point discrimination test. This test, widely used by neurologists to detect the early manifestation of peripheral and central nerve disorders, has been applied to assess the function of regenerating nerves. In 1962, Onne showed that after median nerve suture in adults twopoint discrimination never returned to normal values. Consequently, if the success of surgery in restoring sensation is judged by this test, the results will always be disappointing. However, it has been repeatedly shown by Wynn Parry and Salter (1976), and by Lee Dellon (1981) that excellent function can be regained after nerve suture, even though two-point discrimination remains grossly abnormal. The two-point discrimination test is static: it bears no relation to sensory function as experienced in normal human activities, since object-recognition requires active movement between fingers and thumb.
The second reason why results after repair are expected to be poor is based on the widely-held belief that modality-specific receptors exist in the periphery, and that after suture the majority of fibres are misdirected and do not reach their correct receptors; sensory function is thus bound to be poor. Surgeons have therefore tried to improve function by careful matching of bundles, with fascicular repair under microscopic control. It is now accepted that there are definite morphological correlates to different sensory function (Iggo, in this journal), but, as Mountcastle (1980) stated, it is a big step to correlate what is seen under the microscope with what is actually felt in human sensation. Even the lightest stimulus to a fingertip causes the discharge of multiple receptor units, and when objects are manipulated between the fingers and thumb, a vast array of receptors of various types in skin, joint, blood vessels and tendons are excited.

It is the coding of the temporal and spatial patterns, produced by different stimuli in the many receptors stimulated, which is interpreted centrally and which results in the varieties of sensory experience. However, the specialised corpuscles or receptor endings must be of importance, and it is clearly of great interest to know what happens after division of a nerve. 
In a crush lesion, almost perfect rematching occurs and corpuscles can and do regenerate. Lee Dellon (1981) has shown in the primate that the Meissner's corpuscles degenerate and atrophy after nerve crush but, if re-innervation occurs within up to nine months, the end organs re-form. Clinically, it is well known that almost perfect function returns after crush injuries. Wynn Parry (1981) has described a patient with a total brachial plexus lesion in continuity whose sensory recognition times nearly approached normal 18 months after total denervation. But after nerve division and resuture with a delay of many months or years before the nerve endings reach the periphery, do receptors lie dormant and re-form only when innervated by a nerve fibre? Brooks (personal communication) has described a patient on whom he carried out a median nerve suture 25 years after injury, and in whom protective sensation was subsequently restored to the fingers. In this case it is highly unlikely that receptors were lying dormant for all that time; it is much more likely that the terminal axons were encouraged to respond in some ways to the demands of use, with the central nervous system learning a new code.

There is a widely-held belief that growing nerve fibres crossing a suture line or through a graft will seek their old endoneural tubes, and therefore a careful matching of bundles by interfascicular sutures and grafting, using a microscope, will increase the chances of appropriate connections. However, Morris, Hudson and Weddell in 1972, and more recently Cabaud, Rodkey and Nemeth (1982) showed that the regenerating axons are provided with new endoneural tubes by growing Schwann cells and rarely penetrate the old endoneural tubes. There appear to be two populations of Schwann cells, one responsible for clearing the debris of the old endoneural tubes and the other for creating new ones.

Purves (1982) has reviewed the variety of mechanisms that might guide axons during development and after nerve injury. He concluded that a viable explanation of axon guidance must account for their growth over relatively long distances, during which they appear to have a continual sense of their position; he suggested that only when the nerve reaches the periphery do nerve growth factors, which might attract axons to their correct sites, become operative. While it is obviously correct for a surgeon to match clearly defined bundles, interfascicular suture may nonetheless be illogical because of the constantly shifting architecture of the nerve in its course down the limb. Epineural repair between main branches in the forearm and upper arm may be more appropriate: this relies on the nerves finding their way to the periphery and making logical connections through their supposed intrinsic programming arising centrally. If by constant use the regenerating nerve is encouraged to develop appropriate central engrams (memory traces) such as those of touch, pressure, nociception and changes of temperature, some sensory function might be expected to develop when it reaches the periphery.
Wynn Parry (1981) showed that, many years after nerve suture, patients had very poor sensory function as judged by their ability to recognise objects and textures blindfolded. By contrast, however, remarkable results occur in children and almost normal sensory function is the rule. Since nerve suture is technically more difficult in children, the excellent results must be because the central nervous system is so much more adaptable and plastic in children than in adults, and that children can learn to recode an abnormal sensory profile much more readily. After puberty, this recoding becomes more difficult.

Sensory re-education. More than 20 years ago Wynn Parry (1958) described sensory re-education techniques in which patients were blindfolded and asked to describe variously shaped wooden objects; if unsuccessful, they were to open their eyes and relate what they felt to what they saw, thus trying to recode their sensory maps. They then progressed to the recognition of large objects in daily use, then to smaller objects and then to textures. The time taken to recognise each object or texture and the accuracy of perception were recorded. Periodically, testing was carried out using objects and textures different from those used in re-training. It was shown that, if a patient needed accurate stereognosis in his work or hobbies and was intelligent and co-operative, remarkably good functional results could be obtained. It was also shown that failure to persevere with training or regular appropriate use would lead to deterioration, both of performance and of the results of formal testing.

The importance of sensory re-education after nerve suture has been stressed. Where possible, this should be routine after median nerve repair; if, however, patients are unable to attend for regular re-training sessions, a relative or friend may be shown how to carry out these methods at home. With intensive re-education, several times a day, remarkable sensory functional recovery can be obtained in as little as two or three weeks (Wynn Parry 1981).

Assessment of sensation. How then should we assess sensation in the clinic? During World War II an attempt was made to measure sensation in a manner similar to that used for motor power on the MRC scale, and S grades from 0 to 5 were introduced. The best outcome after repair was S4, defined as the return of superficial pain and tactile sensibility in the autonomous zone, with the disappearance of over-response and recovery of some two-point discrimination. In the MRC report of war injuries (Barnes 1954), only $2.6 \%$ achieved S3, yet $46 \%$ were judged to achieve useful sensory recovery. This represents a criticism of the testing method, not a reflection of the failure of surgery. Function was not tested formally by the ability to recognise objects and textures, nor was it tested by tasks related to the patient's work or hobbies; these can be effected in the occupational therapy department or workshops.

Moberg (1962) introduced the pick-up test, in which small objects are seized between the finger and thumb 
and the time taken to insert them into a box is measured. However, this test suffers from two drawbacks: it requires reasonable intrinsic function, which may be lacking in median nerve lesions or in combined median and ulnar damage, and it does not test sensation only. Lee Dellon, mindful of the criticisms that the static test had aroused, introduced the moving two-point discrimination test (1981). He showed much improved figures with this test, although it does not measure sensation as a functional process, which requires movement to manipulate objects between the thumb and fingers and thus setting up discharges in the receptor organs in several digits and many different types of receptors.

Any test of sensory function should in our view include the patient's ability to recognise objects and textures, and should measure the time taken to do so. Charts have been published by Wynn Parry and Salter (1976) incorporating these ideas and have proved useful in assessing function (Table I). Serial testing is carried out and progress assessed by comparing the number of shapes, textures, large and small objects, and the average time taken for their recognition.

The ability to localise a stimulus accurately to a particular part of the finger and thumb is an important component of sensory function. Paul, Goodman and Merzenich (1972) showed how disorganised the map of localisation (site recognition) becomes after nerve divisions and repair in monkeys: by placing microelectrodes in the contralateral cortex and by making a map of the response of the different parts of the fingers, they were able to show that discrete areas of the cortex were concerned with specific areas of the fingers. After primary suture and immediate division, when time for regeneration had been allowed, the cortical recordings were repeated; the map had become totally disorganised. Thus, re-education of localisation must involve central programming, and this can be carried out with relative ease in some two to three weeks intensive re-training (Wynn Parry and Salter 1976).

Whilst we believe that functional testing is of paramount importance, we continue to measure two-point discrimination since it gives an idea of the number of fibres reaching the periphery and may be a guide to one aspect of surgical success. However, the presence of reinnervated receptors does not itself correlate with function. Jabaley et al. (1976) carried out biopsies of fingertips in patients after nerve suture, and correlated twopoint discrimination, sensory function by object-recognition and the presence of re-innervated receptors. They showed that abundant nerve tissue could be present, but sensory function might remain poor or non-existent. They pointed out that it was not so much the quantity of available nerve tissue, but the use made of it which determined the level of function; motivation and re-training were vital factors. The possibility of sensory overlap from adjacent normal nerves must constantly be kept in mind, and it may be necessary to carry out local anaes- thetic blocks to establish how much sensation is due to this phenomenon.

Abnormal sensation. Hyperaesthesia is quite common after median nerve suture and may inhibit good sensory function, as the patient may find that contact with objects, particularly those that are cold, produces unpleasant sensations. In about $5 \%$ of patients the development of severe causalgia after nerve injuries greatly impairs function. The nature of pain in causalgia has received a great deal of attention in recent years and we now know that there are many factors underlying painful sensations after nerve injury. These include spontaneous firing of the nerve sprouts which, in some patients, persist in considerable numbers at the site of the neuroma. Retrograde nerve sprouts can also track proximally and be the site of ectopic impulse generation. Cross-talk can develop at many levels between abnormally myelinated fibres along the nerve. Nerve sprouts are peculiarly sensitive to noradrenaline, and this may underlie the hyperpathia and burning pain in Sudeck's atrophy (reflex sympathetic dystrophy).

There are also marked central effects of peripheral nerve damage which can be seen within one week of nerve division: these may include abnormal firing in the dorsal root ganglion and dorsal horn cells, central sprouting with abnormal circuits and unmasking of cells that normally do not respond to input from the damaged fibres (Wall and Devor 1978). Thus, a totally altered profile arrives at the central nervous system, generating abnormal central patterns which may be associated with pain. Melzack and Loeser (1978) showed, in a paraplegic man, that painful flexor spasms correlated exactly with spontaneous high frequency discharges recorded by micro-electrodes in the dorsal horn. These pain syndromes can be helped in some $60 \%$ of these patients by a programme of prolonged transcutaneous nerve stimulation (Frampton 1982), serial guanethidine blocks, desensitisation and the encouragement of the use of the hand, followed by sensory re-education (Wynn Parry and Withrington 1984). In the clinic it is not yet possible to correlate nerve fibre patterns picked up by microneurographic techniques and their psychological determinants with response to treatment, but we may hopefully look forward to refinements of these techniques in the future.

Conclusion. The moral for the surgeon is that sensation must be assessed functionally, and only then can the results of different techniques of nerve suture and grafts be truly compared. Physiotherapists and occupational therapists are playing an increasingly important role in the rehabilitation team, both in treatment and in functional assessment. Surgeons who work with their own skilled physiotherapist and occupational therapist know how vital their contribution is to successful surgery. These therapists have shown their ability to make accurate recordings of sensation and are able to provide realistic sensory retraining techniques. It is important that 
Table I. Typical localisation and sensory assessment chart: this patient had impaired function two years after transection of the left-median nerve

Occupation Butcher Age 24 years

Diagnosis Left median nerve lesion Dominant hand Right

Work Unable to maintain firm grip, for example to skin a carcass

Daily activities No problems identified

Hobbies Car maintenance: difficulty performing dextrous activities with left hand, handling nuts and bolts

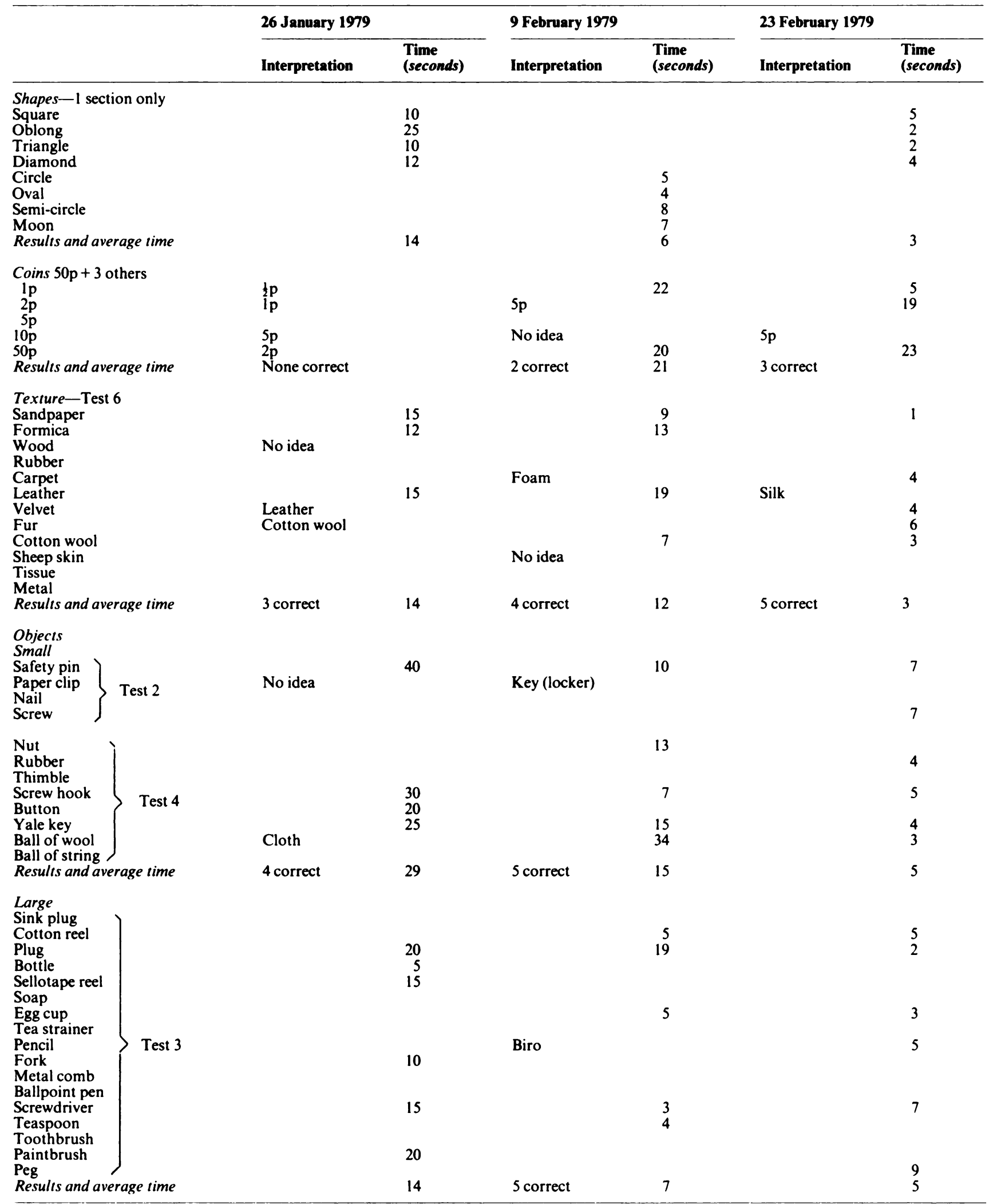


someone other than the surgeon assesses the end results; the combination of the physiotherapists' sensory charting (including object- and texture-recognition times and localisation) with the occupational therapists' report on how the patient actually uses the hand in work and hobbies is a logical way to assess results. Although racial, cultural and work patterns vary so enormously, standard assessments to be used worldwide are nonetheless needed, and one hopes that surgeons and therapists will put their minds to devising simple and realistic charts.

\section{CUTANEOUS SENSORY MECHANISMS}

\section{A. Iggo}

The long debate concerning the sensory functions of the nerves innervating the skin can now be regarded as settled. Experimental methods derived from several disciplines-ranging from histology to psychophysicshad established some general principles, such as the role of large myelinated axons in tactile sensations and that of the smallest ones in pain and temperature; there was, however, still dispute about the concepts of "specificity" and "pattern theory" until 1965. The last two decades have yielded important new information about the existence and morphology of sensory receptors in the skin (using electron microscopy); the physiological characteristics of the sensory receptors (using quantitative electrophysiological techniques); the correlation between morphology and physiology; and the actual role of individual sensory receptors and afferent fibres.

The first three advances, already summarised by the author (Iggo 1977), came from mammalian experiments and established the unequivocal existence of morphologically distinct sensory receptors with physiologically distinct capabilities for detecting various kinds of natural stimuli. For example, there are four basic kinds of tactile receptor with large myelinated axons in non-hairy skin (Pacinian corpuscles, Meissner corpuscles, Merkel discs and Ruffini endings), and two kinds of thermoreceptor with fine myelinated or non-myelinated axons. Nerve injury, such as traumatic crush of a peripheral nerve, leads initially to degeneration of the peripheral part of the nerve and the neural component of the sensory receptor. Regeneration after such a crush can lead to re-innervation of the old sensory receptor with recovery of function. Reunion of cut nerves can also lead to regeneration, but this is less certain and recovery is only partial (Horch 1979). When the regenerating nerve is prevented from growing back to its old site, as in the formation of a neuroma, an abnormal excitability of the surviving nerve terminals may develop. Causalgia is an example of a condition that can result from partial injury of a peripheral nerve and failure to restore normal innervation.

A major breakthrough in understanding individual sensory receptors and afferent fibres resulted when percutaneous recording from peripheral nerves in conscious human subjects was developed and applied to the study of sensory receptors in the skin (Vallbo and Hagbarth 1968). Confirmation of the existence in man of the kinds of sensory receptors described in mammals was an early result (Johansson and Vallbo 1983), especially receptors with large myelinated axons. It was some time before the smaller axons were analysed, but Torebjörk and Hallin (1979) have now confirmed the existence in man of nociceptors with non-myelinated axons. The thermoreceptors, however, still present a problem.

A central question concerns the role that individual afferent units (that is, the sensory receptors and associated dorsal root ganglion neurones) play in sensation. A corollary to this question is whether one kind of afferent unit can substitute in sensation for another. Direct answers have been given in experiments on conscious, co-operating human subjects (Gybels, Handwerker and Van Hees 1979; Ochoa and Torebjörk 1983), in whom the percutaneous micro-electrode technique was combined with psychophysical testing. One method attempted to correlate the subject's perception of the quality and location of a peripheral cutaneous stimulus with the characteristics of the receptive field and the location of the afferent unit which was recorded. In a more sophisticated analysis these results were supplemented by electrical stimulation of the afferent unit through the recording electrodes (intraneural microstimulation) in the median or ulnar nerve (Ochoa and Torebjörk 1983).

The results are illuminating and also decisive, since rigorous controls were used to guard against incidental stimulation of axons other than the one investigated. The sensation evoked by impulses in a single myelinated fibre innervating a low-threshold mechanoreceptor had quantifiable attributes of quality, magnitude and local sign. Several distinct "elementary" sensations could be aroused and correlated with the kind of afferent unit, as follows:

Rapidly-adapting units which have Meissner corpuscles evoked a sensation of intermittent non-painful tapping on electrical stimulation at low frequency. Single shocks, which would have elicited only a single impulse, were often recognised as taps. Increasing the frequency of electrical stimulation caused a gradual change in the sensation, from tapping to oscillatory flutter-vibration at about 
100/s. The sensation was consistent, and did not have the quality of pressure or tickling. heat or cold or pain at any frequency or pattern of stimulation.

Slowly-adapting units, Type $I$, which have Merkel cells and discs as their receptors evoked a pure, elementary sustained sensation of pressure, in contrast to the response to stimulation from rapidly-adapting units. Single impulses, however, were not felt and the threshold minimum frequency was from 3 to $10 / \mathrm{s}$. Higher frequencies increased the magnitude of the perceived pressure.

$P C$ units with Pacinian corpuscles as their receptors, evoked sensations of tickling or vibration, but with threshold frequencies that varied between 10 and $80 / \mathrm{s}$. The frequency of the perceived vibration changed systematically as the frequency of stimulation increased up to about $300 / \mathrm{s}$.

Slowly-adapting units, Type II, the fourth category of mechanoreceptor in palmar skin with Ruffini endings as the receptor, did not evoke any elementary sensation.

In another series of experiments, Gybels et al. (1979) explored the role of nociceptors with $\mathrm{A}$ and $\mathrm{C}$ fibres, and reported a weak correlation between the frequency of discharge evoked by thermal, mechanical or chemical stimulation and the intensity of the sensation of pain aroused. Activity in the C-nociceptors evoked different elementary sensations from those caused by the mechanoreceptors (see above).

An important conclusion from these experimental results is that sensory activity initiated in "specific" cutaneous receptors can result in distinct, reproducible "specific" sensations, of which the quality is related to the degree of activity and the "perceived" receptive field is coincident with the actual location of the sensory receptor in the skin. These results have important neurological and neurosurgical implications since they allow a more accurate assessment of the consequences of injury or surgical manipulation of peripheral nerves. Since the afferent units appear to have unique sensory functions, it can be expected that aberrant activity might lead to bizarre sensations.

The central processing of sensory information from some cutaneous receptors can preserve the encoding that starts in the skin, as is clear from the results reviewed above. Nevertheless, those afferent units that enter and end in the dorsal horn of the spinal cord are subject to a considerable degree of interaction and modulation of their sensory information. This influences, and may determine, the information that goes on to higher levels of the sensory pathways. These interactions can arise from an interplay of excitation and inhibition at local segmental levels of the spinal cord among the inputs from the cutaneous receptors. An example is the suppression of an excitatory action of nociceptors by concurrent activity in mechanoreceptors. The inhibitory or blocking effect can be quite potent and may totally prevent the onward flow of noxious information in ascending sensory pathways (Cervero, Iggo and Ogawa 1976).

A second potent source of control of the onflow of sensory information comes from higher levels of the central nervous system. A number of different systems are involved, including brain-stem nuclei such as the median raphe, the locus ceruleus and the peri-aqueductal grey matter, as well as still higher levels such as the sensorimotor cortex. These descending controls may have selective actions that, by preferentially affecting inputs from one class of cutaneous receptor, can determine which kind of sensory information is allowed to enter the ascending sensory pathways. Mechanisms of this kind are active at each synaptic relay on the sensory path, including the dorsal horn of the spinal cord, dorsal column nuclei at the rostral end of the spinal cord and various nuclei in the thalamus. It is also necessary to take account of the role at different sites of neuropeptides, such as vasoactive intestinal peptide, substance $P$, the endorphins and opioids (Gebhart 1982), in addition to the classical synaptic transmitters such as noradrenaline, 5-HT and GABA. The roles of these diverse chemicals and the mechanisms of their actions in cutaneous sensibility, although still to be established, offer future therapeutic opportunities. The latter will emerge as the former are successfully mastered.

The ultimate challenge of understanding the cortical processes underlying consciousness and perception is unlikely to yield to intellectual enquiry for a long time yet, but it is already clear that the subcortical processes are much better understood than they were two decades ago. This new knowledge provides a secure foundation for further enquiry, and should lead to the direction of future investigations into fruitful avenues.

\section{REFERENCES}

Lesions of peripheral nerves: the present position

Alpar EK, Brooks DM. Long-term results of ulnar to median nerve pedicle grafts. Hand 1978:10:61 4.

Bonney G. Value of axon responses in determining site of lesion in traction injuries of the brachial plexus. Brain 1954;77:588-609.

Bonney G. Peripheral nerve lesions: management. In: Harris NH, ed. Postgraduate textbook of clinical orthopaedics. Bristol etc: Wright. 1983:712 30 .
Bonney G, Gilliatt RW. Sensory nerve conduction after traction lesions of the brachial plexus. Proc $R$ Soc Med 1958:51:365-7.

Bonney G, Birch R, Jamieson AM, Eames RA. Experience with vascularized nerve grafts. Clin Plast Surg 1984;11(1):137-42.

Breidenbach W, Terzis JK. The anatomy of free vascularized nerve grafts. Clin Plast Surg 1984;11(1):65-71.

Campbell Reid DA. The neurovascular island flap in thumb reconstruction. Br J Plast Surg 1966;19:234 44. 
Clawson DK, Seddon HJ. The late consequences of sciatic nerve injury. J Bone Joint Surg [Br] 1960:42 B:213 25

Comtet JJ, Bertrand HG, Moyen B, Condamine JL. Greffe nerveuse vascularisée utilisant le brachial cutané interne transplanté avec un pédicule vasculaire: technique de prélèvement. Lyon Chir 1981 ; 77(1):62 3 .

Gilbert A. Vascularized sural nerve graft. Clin Plast Surg 1984:11(1):73- 7.

Hakstian RW. Funicular orientation by direct stimulation: an aid to peripheral nerve repair. J Bone Joint Surg $[\mathrm{Am}]$ 1968:50 A $1178-86$.

Jamieson AM, Eames RA. Reimplantation of avulsed brachial plexus roots: an experimental study in dogs. Int J Microsurg 1980;2: 7580 .

Jones SJ. Investigation of brachial plexus traction lesions by peripheral and spinal somatosensory evoked potentials. J Neurol Neurosurg Psichiatr. 1979:42:107 16.

Millesi H. Meissl G, Berger A. The interfascicular nerve grafting of the median and ulnar nerves. $J$ Bone Joint Surg $[\mathrm{Am}]$ 1972:54 A 72750.

Narakas A. Surgical treatment of traction injuries of the brachial plexus. Clin Orthop 1978:133:71 90

Narakas A. Neurolysis in traction lesions of the brachial plexus. Paper read at international meeting on brachial plexus surgery, $\mathbf{S}$ Mary`s Royal National Orthopaedic Hospitals. January 1983.

Iatrogenic injuries of nerves

Aho K, Sainio K, Kianta M, Varpanen E. Pneumatic tourniquet paralysis: case report. J Bone Joint Surg [Br] 1983:65 B:441 3.

Bonney V. A texthook of gynaecological surgery. 5th ed. London etc: Cassell and Co, 1947:55.

Harris NH. Postgraduate textbook of clinical orthopaedics. Bristol etc: PSG Wright. 1983:19.580.

Trotter W. Collected papers. London: Oxford University Press (H Milford). 1941:4 5 .

Sensation

Barnes R. Causalgia-a review of 48 cases. In: Peripheral nerve injuries. MPC Special Report Series No. 282. London: HMSO, 1954 $156-85$.

Cabaud HE, Rodkey G, Nemeth TJ. Progressive ultrastructural changes after peripheral nerve transection and repair. $J$ Hand Surg 1982:7:353-65.

Frampton VM. Pain control with the aid of transcutaneous nerve stimulation. Physiotherapy 1982;68:77-81.

Jabaley ME, Burns JE, Orcutt BS, Bryant WM. Comparison of histologic and functional recovery after peripheral nerve repair. $J$ Hand Surg 1976;1:119-30.

Lee Dellon A. Evaluation of sensibility and re-education of sensation in the hand. Baltimore: Williams \& Wilkins 1981.

Melzack R, Loeser JD. Phantom body pain in paraplegics; evidence for a central "pattern generating mechanism" for pain. Pain 1978;4: 195-250.

Moberg $\mathbf{E}$. Criticism and study of methods for examining sensibility in the hand. Neurology (Minneap) 1962;12:8-19.

Morris JH, Hudson AR, Weddell G. A study of degeneration and regeneration in a divided rat sciatic nerve based on electron microscopy II. The development of the "regenerating unit". Z Zellforsch 1972a:124:103-30.

Morris JH, Hudson AR, Weddell G. A study of degeneration and regeneration in a divided rat sciatic nerve based on electron microscopy. IV. Changes in fascicular microtopography, perineurium and endoneurial fibroblasts. Z Zellforsch 1972b;124:165-203.

Cutaneous sensory mechanisms

Cervero F, Iggo A, Ogawa H. Nociceptor-driven dorsal horn neurones in the lumbar spinal cord of the cat. Pain 1976:2:5-24.

Gebhart GF. Opiate and opioid peptide effects on brain stem neurones: relevance to nociception and antinociceptive mechanisms. Pain $1982 ; 12: 93-140$.

Gybels J, Handwerker HO, Van Hees J. A comparison between the discharges of human nociceptive nerve fibres and the subject's ratings of his sensations. J Physiol 1979;292:193 206.

Horch $\mathbf{K}$. Guidance of regrowing sensory axons after cutaneous nerve lesions in the cat. $J$ Neurophysiol 1979;42:1437 49

Iggo A. Cutaneous and subcutaneous sense organs. Br Med Bull 1977; 33:97-102.
Narakos AO. Operative treatment for radiation-induced and metastatic brachial plexopathy in 45 cases, 15 having an omentoplasty. Bull Hosp Jt Dis Orthop Inst 1984:44:354 75.

Raji ARM, Bowden REM. Effects of high-peak pulsed electromagnetic field on the degeneration and regeneration of the common peroneal nerve in rats. J Bone Joint Surg $[B r]$ 1983;65 B:478 92.

Rank BK, Wakefield AR, Hueston JT. Surgery of repair as applied to hand injuries. 4th ed. Edinburgh and London: Churchill Livingstone, 1973.

Seddon HJ. Surgical disorders of the peripheral nerves. 2nd ed. Edinburgh etc: Churchill Livingstone, 1975

Strange FG St Clair. Case report on pedicled nerve grafts. Br J Surg 1950:37:331.

Sunderland S. Nerves and nerve injuries. 2nd ed. Edinburgh etc Churchill Livingstone, 1978.

Taylor GI, Ham FJ. The free vascularised nerve graft: a further experimental and clinical application of microvascular techniques. Plast Reconstr Surg 1976:57:413 26.

Terzis J, Faibisoff B, Bruce Williams H. The nerve gap: suture under tension vs. graft. Plast Reconstr Surg 1975:56:166 70.

Wynn Parry CB, Salter M. Sensory re-education after median nerve lesions. Hand 1976:8:250 7 .

Yeoman PM. Cervical myelography in traction injuries of the brachial plexus. J Bone Joint Surg [Br] 1968:50 B:253 60

Wadsworth TG. The external compression syndrome of the ulnar nerve at the cubital tunnel. Clin Orihop 1977:124:189-204.

Wadsworth TG, Brooks DM. Neurological disorders. In: Wadsworth TG. ed. The elhow: Edinburgh etc: Churchill Livingstone. 1982 ; 271 .

Weber ER, Daube JR, Coventry MB. Peripheral neuropathies associated with total hip arthroplasty. J Bone Joint Surg $[\mathrm{Am}]$ 1976; 58-A:66-9.

Mountcastle VB, ed. Medical physiology. 14th ed. St Louis etc: CV Mosby, 1980;61-3.

Onne $\mathbf{L}$. Recovery of sensibility and sudomotor activity in the hand after nerve suture. Acta Chir Scand 1962: Suppl 300:1-69.

Paul RL, Goodman H, Merzenich M. Alterations in mechanoreceptor input to Brodmann's areas $I$ and 3 of the postcentral hand area of Macaca mulatto after nerve section and regeneration. Brain Res 1972;39:1-19.

Purves D. Guidance of axons during development and after nerve injury. In: Nicholls JG, ed. Repair and regeneration of the nervous system. Berlin etc: Springer-Verlag, 1982:107-25.

Wall PD, Devor M. Physiology of sensation after peripheral nerve injury, regeneration, and neuroma formation. In: Waxman SG. ed. Physiology and pathohiology of axons. New York: Raven Press. 1978:377-88.

Wynn Parry CB. Rehabilitation of the hand. London: Butterworth, 1958.

Wynn Parry CB, Salter M. Sensory re-education after median nerve lesions. Hand 1976:8:250 7 .

Wynn Parry CB. Rehahilitation of the hand. 4th ed. London: Butterworth, 1981.

Wynn Parry CB, Withrington RH. Painful disorders of peripheral nerves. Postgrad Med J 1984;60:869 75.

Johansson RS, Vallbo AB. Tactile sensory coding in the glabrous skin of the human hand. Trends in neurosciences 1983;6:27 32 .

Ochoa J, Torebjörk E. Sensations evoked by intraneural microstimulation of single mechanoreceptor units innervating the human hand. J Physiology 1983:342:633-54.

Torebjörk HE, Hallin RG. Microneurographic studies of peripheral pain mechanisms in man. Advances in pain research and therapy. 1979:3:121-31.

Vallbo AB, Hagbarth KE. Activity from skin mechanoreceptors recorded percutaneously in awake human subjects. Exp Neurol 1968:21:270 89 